\title{
Long-term antidepressant use: patient perspectives of benefits and adverse effects
}

\author{
This article was published in the following Dove Press journal: \\ Patient Preference and Adherence \\ 28 July 2016 \\ Number of times this article has been viewed
}

\author{
Claire Cartwright ${ }^{\prime}$ \\ Kerry Gibson' \\ John Read ${ }^{2}$ \\ Ondria Cowan' \\ Tamsin Dehar' \\ 'School of Psychology, University of \\ Auckland, New Zealand; ${ }^{2}$ Psychology \\ Department, University of East \\ London, Stratford Campus, \\ London, UK
}

\begin{abstract}
Long-term antidepressant treatment has increased and there is evidence of adverse effects; however, little is known about patients' experiences and views of this form of treatment. This study used mixed methods to examine patients' views and experiences of long-term antidepressant treatment, including benefits and concerns. Data from 180 patients, who were long-term users of antidepressants (3-15 years), were extracted from an anonymous online survey of patients' experiences of antidepressants in New Zealand. Participants had completed rating scales about the effectiveness of antidepressants, levels of depression before and during antidepressant use, quality of life, and perceived adverse effects. Two open-ended questions allowed participants to comment on personal experiences. The majority (89.4\%) reported that antidepressants had improved their depression although 30\% reported moderate-to-severe depression on antidepressants. Common adverse effects included withdrawal effects $(73.5 \%)$, sexual problems (71.8\%), and weight gain (65.3\%). Adverse emotional effects, such as feeling emotionally numb (64.5\%) and addicted (43\%), were also common. While the majority of patients were pleased with the benefits of antidepressant treatment, many were concerned about these adverse effects. Some expressed a need for more information about long-term risks and increased information and support to discontinue.
\end{abstract}

Keywords: antidepressants, patients' experiences, patients' beliefs, adverse effects, withdrawal symptoms, discontinuation syndrome

\section{Introduction}

Antidepressant treatment can be viewed as having both short- and long-term aspects with short-term treatment including the acute and continuation phase, and long-term treatment including the maintenance phase. ${ }^{1,2}$ Increases in long-term antidepressant treatment of depression have contributed to the rise in antidepressant use. ${ }^{3,4}$ An examination of data from the United Kingdom General Practice database for the first antidepressant prescriptions between 1993 and 2005 found that the average number of prescriptions per patient doubled from 2.8 to 5.6 and a proportion of patients received, on average, 35 prescriptions over a 5-year period. ${ }^{4}$ It has been argued that patients with histories of recurrent depressive episodes may require long-term or indefinite treatment with antidepressants. ${ }^{5,6}$ Changes in prescribing guidelines have also shifted toward longer term maintenance treatment. A recent international review of 13 sets of prescribing guidelines revealed that recommendations for duration of continuation treatment varied from 4 to 12 months and maintenance treatment from 1 year to lifelong or indefinite. ${ }^{7}$

While there is evidence for continuation of antidepressant treatment after remission, there is less evidence for maintenance or longer term treatment. ${ }^{8}$ While most cases of depression are managed through primary care, ${ }^{9}$ a recent review revealed that no randomized clinical trials have been conducted to evaluate the efficacy of (c)
hereby accept the Terms. Non-commercial uses of the work are permitted without any further permission from Dove Medical Press Limited, provided the work is properly attributed. For permission for commercial use of this work, please see paragraphs 4.2 and 5 of our Terms (https://www.dovepress.com/terms.php). 
long-term treatment in primary care ${ }^{10}$ However, a review of 14 naturalistic studies of long-term treatment for depression over 10 years found that outcomes for depressed patients were poor, with multiple relapses and large variability, both within and between individuals. ${ }^{10}$ Patients in nondrug-treated samples did not show worse outcomes, while some had superior outcomes. Furthermore, a study of antidepressant use over 2 years in primary and secondary clinical care found high rates of recurrence $(60 \%-63 \%)$ in patients continuously using adequate dosages of antidepressants. ${ }^{11}$ Patients not treated with antidepressants after remission had the lowest recurrence rate $(26 \%){ }^{11}$

A recent investigation of patient-perceived side effects in the Netherlands found that $63 \%$ of patients reported, on average, $2.9 \%$ side effects during the $1-2$ years of follow-up period. ${ }^{12}$ The researchers used a 12 -item shortened version of the Antidepressant Side-Effect Checklist that included insomnia, sleepiness during the day, restlessness, muscle spasms/twitching, dry mouth, profuse sweating, sexual disorders, nausea, constipation, diarrhea, weight gain, and dizziness. ${ }^{12}$ The most frequently reported side effects for selective serotonin reuptake inhibitors (SSRIs) were dry mouth, profuse sweating, sexual dysfunction, and weight gain. ${ }^{12}$ Two recent reviews of research in this area concluded that discontinuation effects, sexual dysfunction, weight gain, and sleep disturbance (multiple long-wake periods) are adverse effects of long-term SSRI use. ${ }^{13,14}$ There is also increased risks of osteoporosis and fracture, bleeding disorders, hyponatremia, ${ }^{13,14}$ and diabetes mellitus. ${ }^{15}$

It is also important to note that qualitative research has revealed a range of emotional adverse effects that are not investigated in the majority of studies, including the study mentioned earlier. ${ }^{12}$ A literature review of research into patients' perspectives of antidepressants found that these included sedative-type effects, emotional blunting, and emotional instability. ${ }^{16}$ These adverse effects are often not investigated and are not mentioned, both on drug packaging and in advertising. ${ }^{17}$ Hence, adverse effects that impact emotional well-being are often ignored.

The data for this study came from a large online survey of patients' experiences of antidepressants in New Zealand $(\mathrm{N}=1,829) .{ }^{18}$ This survey aimed to gain insight into patients' perspectives of antidepressant medication. Approximately $50 \%$ of participants reported being on antidepressants for $\geq 3$ years. Those who had used antidepressants for $>3$ years reported more severe side effects, including "weight gain", "addiction", "feeling not like myself", "withdrawal symptoms", and "suicidality", than those who had been on antidepressants for $\leq 2$ years. ${ }^{18}$
Little is known about patients' perspectives on long-term antidepressant use. To gain insight into patients' experiences of the benefits and problems associated with this form of treatment, this study examines the experiences of patients who participated in the New Zealand survey and first began using antidepressants in the 1997-2001 period. It asks the following questions: What are the patient-perceived benefits of long-term antidepressant use? What are the patientperceived risks or concerns about long-term use?

\section{Methods}

\section{Instruments and procedure}

Ethics approval was given for the original survey by the University of Auckland Human Subjects Ethics Committee (Ref: 7340). The original anonymous online survey was advertised through the New Zealand media. Consent was indicated by participation in the anonymous survey. Criteria for participation included having used an antidepressant in the previous 5 years and being 18 years of age or older. Participants completed rating scales, including levels of depression before and during antidepressant treatment, perceived effectiveness of antidepressants, perceived impact on the quality of life, and perceived adverse effects. The survey also contained open-ended questions. These included the following:

1. Could you please complete this sentence or paragraph:

"In my life, antidepressants have been ....?"

2. If there is anything you would like to say about your experiences of antidepressants, please write about this in the box below.

Further information about the study methods is available from the original study. ${ }^{14}$

Researchers have used various criteria in the study of long-term antidepressant treatment, including 18 months, ${ }^{18}$ 2 years, ${ }^{11}$ and $\geq 10$ years. ${ }^{12}$ The original survey provided a series of options in terms of the length of antidepressant use. The maximum available to participants was $\geq 3$ years. To access a subgroup of participants who had used antidepressants for longer term, the criteria for participation in this study were having begun antidepressant treatment between 1997 and 2001, having used antidepressants in the 5 years before completing the survey, and having used antidepressants for a minimum of 3 years. Participants in the original (and current) study who reported using medications that were not antidepressants were excluded from the study.

\section{Participants}

The participants in the study were 180 adults (Table 1). Of these, 149 were prescribed antidepressants by their general practitioner and 31 by a psychiatrist. Some participants 
Table I Participant characteristics

\begin{tabular}{lll}
\hline Variable & $\mathbf{N}=\mathbf{l} \mathbf{8 0}$ & $\mathbf{( \% )}$ \\
\hline $\begin{array}{l}\text { Age, years } \\
\text { I8-25 }\end{array}$ & $\mathrm{I}$ & \\
$26-35$ & 45 & $(0.5)$ \\
$36-45$ & 54 & $(25.0)$ \\
$46-55$ & $5 \mathrm{I}$ & $(29.5)$ \\
$56-65$ & 25 & $(28.3)$ \\
$66+$ & 5 & $(13.7)$ \\
Sex & & $(2.7)$ \\
Female & 143 & \\
$\quad$ Male & 37 & $(79.4)$ \\
Taking antidepressants & 151 & $(20.6)$ \\
Not taking antidepressants & 29 & $(83.8)$ \\
\end{tabular}

noted in their written comments how many years they had been on antidepressants. The available data indicates that the participants in this study were on antidepressant medication for 3-15 years. The most commonly prescribed antidepressants were citalopram (23\%), venlafaxine (18\%), paroxetine (13\%), 21 fluoxetine (13\%), loxamine (7\%), and nortriptyline (3\%).

\section{Data analysis}

Descriptive statistics were calculated for the quantitative data from the rating scales using IBM SPSS Statistics for Windows, Version 20.0 (IBM Corporation, Armonk, NY, USA).

Qualitative data from both open-ended questions were combined - all participants ( $\mathrm{N}=180)$ answered the first question, and 108 participants the second. A categorical analysis, based on the methods described by Bowling, ${ }^{19}$ was conducted on the qualitative data. All the data were read and reread to develop an understanding of the views and experiences expressed. Patterns were examined in the combined data set by the first, fourth, and fifth authors independently. Three main categories of response were identified by each of the authors. These included a category of positive statements about the benefits of antidepressants, a category of statements about the problematic aspects, and a third category of statements regarding other concerns and preferences. These were further examined for subcategories. The data were then entered into SPSS 20 and the frequencies for each category and subcategory were calculated.

\section{Results}

\section{Levels of depression and quality of life}

As can be seen from Table 2, the respondents reported an overall improvement in levels of depression and quality of life while on antidepressants, although $30.7 \%$ reported moderate-to-severe depression while on antidepressants.
Table 2 Participant ratings of levels of depression and quality of life before and during antidepressant treatment

\begin{tabular}{lll}
\hline Variable & $\mathbf{N}=\mathbf{l} \mathbf{8 0}$ & $\mathbf{( \% )}$ \\
\hline Level of depression in year before taking antidepressants & \\
Not at all & 7 & $(3.9)$ \\
Mild & 22 & $(12.2)$ \\
Moderate & 66 & $(37.0)$ \\
Severe & 85 & $(47.0)$ \\
Did antidepressants reduce depression & 160 & \\
Yes & 19 & $(89.4)$ \\
No & 97 & $(10.6)$ \\
Quality of life while taking antidepressants \\
Greatly improved \\
Slightly improved & 65 & \\
Unchanged & 5 & $(53.9)$ \\
Slightly worse & 4 & $(31.6)$ \\
A lot worse & 9 & $(2.8)$ \\
Level of depression while taking antidepressants $(\mathrm{n}=179)$ & $(2.2)$ \\
Not at all & 35 & $(5.0)$ \\
Mild & 89 & $(19.6)$ \\
Moderate & 39 & $(49.7)$ \\
Severe & 16 & $(21.8)$ \\
\hline
\end{tabular}

\section{Adverse effects}

Ten adverse effects were reported by more than half of the participants (Table 3). The five most commonly selected adverse effects were withdrawal effects (73.5\%), sexual difficulties (71.8\%), weight gain (65.3\%), feeling emotionally numb (64.5\%), and failure to reach orgasm (64.5\%). Between $36 \%$ and $57 \%$ of respondents experienced these adverse effects at either a moderate or severe level. Participants also reported a number of other emotional effects, including "feeling not like myself" (54.4\%), "reduced positive feelings" (45.6\%), "caring less about others" (36.4\%), and "suicidality" (36\%).

\section{Qualitative analysis}

As outlined in the "Methods" section, three main categories of response were defined from the analysis of the combined qualitative data set. An overview is presented in Table 4.

\section{They helped me to cope with life}

Just over two-thirds of participants wrote that antidepressants had helped them to get by or cope, and around one-fifth thought that they had functioned well as a result of being on an antidepressant.

As one participant said,

A necessary part of life that makes it easier to cope with the dramas that life gives me. Over the past few years I have experienced several major life events [...] I do not think I would have coped with these events without the use of antidepressants. [P. 60]. 
Table 3 Participant ratings of adverse effects

\begin{tabular}{|c|c|c|c|c|c|c|c|c|c|}
\hline \multirow[t]{2}{*}{ Adverse effects } & \multirow{2}{*}{$\begin{array}{l}\text { Number of } \\
\text { responses }\end{array}$} & \multicolumn{2}{|c|}{ Any level } & \multicolumn{2}{|c|}{ Mild } & \multicolumn{2}{|c|}{ Moderate } & \multicolumn{2}{|c|}{ Severe } \\
\hline & & $\mathbf{N}$ & (\%) & $\mathbf{N}$ & (\%) & $\mathbf{N}$ & (\%) & $\mathbf{N}$ & (\%) \\
\hline Withdrawal effects & 155 & 114 & $(73.5)$ & 26 & $(16.8)$ & 36 & $(23.2)$ & 52 & (33.5) \\
\hline Sexual difficulties & 174 & 125 & (7I.8) & 48 & (27.6) & 46 & $(26.4)$ & 31 & $(17.8)$ \\
\hline Weight gain & 170 & 111 & $(65.3)$ & 45 & $(26.5)$ & 42 & $(24.7)$ & 24 & $(14.1)$ \\
\hline Feeling emotionally numb & 169 & 109 & $(64.5)$ & 48 & (28.4) & 44 & $(26.0)$ & 17 & $(10.1)$ \\
\hline Failure to reach orgasm & 172 & 111 & $(64.5)$ & 29 & (16.9) & 50 & $(29.1)$ & 32 & (18.6) \\
\hline Dry mouth & 172 & 100 & $(58.1)$ & 45 & (26.2) & 32 & (I8.6) & 23 & (13.4) \\
\hline Agitation & 167 & 92 & $(55.1)$ & 51 & (30.5) & 29 & $(17.4)$ & 12 & $(7.2)$ \\
\hline Drowsiness & 173 & 95 & (54.9) & 44 & $(25.4)$ & 38 & $(22.0)$ & 13 & (7.5) \\
\hline Feeling not like myself & 169 & 92 & $(54.4)$ & 53 & (3I.4) & 26 & (I5.4) & 13 & (7.7) \\
\hline Dizziness & 173 & 92 & $(53.2)$ & 58 & (33.5) & 26 & $(I 5.0)$ & 8 & $(4.6)$ \\
\hline Reduced positive feelings & $17 \mid$ & 78 & $(45.6)$ & 45 & (26.3) & 20 & (II.7) & 13 & (7.6) \\
\hline Addiction & 165 & 71 & $(43.0)$ & 26 & (15.8) & 22 & (I3.3) & 23 & (13.9) \\
\hline Headaches & 170 & 72 & $(42.4)$ & 39 & (22.9) & 21 & $(12.4)$ & 12 & (7.1) \\
\hline Caring less about others & 165 & 60 & $(36.4)$ & 40 & $(24.2)$ & II & $(6.7)$ & 9 & (5.5) \\
\hline Suicidality & 172 & 62 & $(36.0)$ & 30 & (17.4) & 15 & (8.7) & 17 & (9.9) \\
\hline Nausea & 167 & 60 & (35.9) & 40 & $(24.0)$ & 16 & $(9.6)$ & 4 & (2.4) \\
\hline Tremors & 173 & 57 & (32.9) & 36 & (20.8) & 9 & (5.2) & 12 & (6.9) \\
\hline Feeling aggressive & $17 \mid$ & 54 & (31.6) & 31 & $(18.1)$ & 14 & $(8.2)$ & 9 & $(5.3)$ \\
\hline Diarrhea & 163 & 41 & $(25.2)$ & 23 & $(14.1)$ & 14 & (8.6) & 4 & (2.5) \\
\hline Weight loss & 157 & 24 & (I5.3) & 13 & $(8.3)$ & 7 & (4.5) & 4 & (2.5) \\
\hline
\end{tabular}

One woman talked about her perception that the antidepressants helped her to have a "normal life":

In my life antidepressants have been very useful. I am now a very functional human being and can lead an absolutely normal life with no problems whatsoever. [P. 7].

\section{Problems with antidepressants}

In this category, participants wrote mainly about a long process of finding an antidepressant that "worked", problems

Table 4 Categories of qualitative responses

\begin{tabular}{ll}
\hline Categories of response & $\begin{array}{l}\text { Frequency (\%) } \\
(\mathbf{N}=180)\end{array}$ \\
\hline They helped me cope with life & \\
Help to get by & 64.4 \\
Help to function well & 21.7 \\
Problems with antidepressants & \\
Withdrawal & 21.1 \\
Impact on self & 17.8 \\
Long process & 18.3 \\
Ineffective & 8.9 \\
$\quad$ Not worked & 6.1 \\
Made life worse & 4.4 \\
Other adverse effects & 18.9 \\
Beyond antidepressants & \\
The importance of alternative treatments & 26.1 \\
Need accurate or more information & 11.1 \\
Prescriber roles & 15.6 \\
Want to stop & 11.1 \\
\hline
\end{tabular}

with discontinuation, the negative impact of antidepressants on views of self, and other adverse effects.

Some participants talked about the years it took to find an antidepressant that was effective for them.

It did, however, take many years of trying different types of antidepressants before I found one that seemed to work for me and had few side effects or side effects that were manageable. [P. 133].

As noted earlier, $74 \%$ of participants reported problems with withdrawal symptoms and $21 \%$ wrote about problems with withdrawal in the open-ended questions. Some commented that they had not been informed about the difficulties of withdrawing from antidepressants after long-term use.

I was never informed by doctors of long-term side effects or addiction/development of tolerance and went through extremely severe withdrawal symptoms attempting to get off (suicidal level depression). Only by persisting through terrible suffering did I wean myself off. [P. 98].

Some felt unable to discontinue antidepressant treatment as a result. For the woman below, this resulted in a lack of options with regard to managing her depression.

While there is no doubt I am better on this medication, the adverse effects have been devastating - when I have tried to withdraw with "head zaps", agitation, insomnia and mood changes. This means that I do not have the option of 
managing the depression any other way because I have a problem coming off this medication. [P. 102].

Some talked about the ways in which taking antidepressants impacted their views of themselves. This included feeling abnormal for needing an antidepressant and having difficulty knowing what is "actually me" as opposed to the effects of the antidepressant.

I have been on them for so long now that I'm not sure how much of myself is actually me and how much is the antidepressant. [P. 56].

One woman wrote about a number of these concerns, including the impact of long-term use on her brain.

Have now been taking SSRIs for better part of 15 years. Whenever I have tried to stop, I find I "relapse" or experience withdrawal symptoms. I worry that my brain chemistry has been permanently affected, so I now feel I cannot be "normal" without them [...] I try to get off them but can't seem to do it, no matter how slowly I wean myself off. [P. 80].

Other adverse effects written about by participants included increases in numbing or emotional bluntness, suicidality, weight gain, and sexual problems.

Something I have been told to take but I do not like them. They numb all your feelings, both positive and negative. [P. 55].

I have been permanently damaged sexually by the drugs. [P. 98].

I have tried numerous antidepressants with severe side effects $[\ldots]$ when on some of them my mood has lowered to feeling suicidal. [P. 125].

\section{Beyond antidepressants}

Participants reflected on a number of concerns, including the importance of receiving therapy, the need for accurate and full information about long-term use, and the role of prescribers. Of these participants, $26 \%$ wrote about alternatives to antidepressants. Some commented that antidepressants are not the only alternative that can help with recovery.

Antidepressants are seen as a cure all and this forgets all the other things that help. [P. 56].

Antidepressants in combination with moderate amounts of exercise, flexible working hours, meditation/mindfulness and supportive relationships are key for me to maintain wellness in my life. [P. 133].

Thirty participants (17\%) also wrote about the importance of therapy or counseling as part of their treatment. As the participants below said,
I believe the antidepressants helped, but I needed a counsellor to help me work through some of the causes [...] I had been depressed on and off since teenage years. CBT has given me the skills to cope with life on a daily basis without drugs (most of the time). [P. 89].

I believe that I did have depression and that it was a result of a series of stressful experiences over a long duration. Affordable access to a psychologist would have negated the requirement for medication. What resolved my depression in the end was visiting a psychologist regularly over a couple of years [...] this was very expensive, but worth it. [P. 65].

Some also expressed frustration that the therapy was not more easily available. As one prescriber who had used antidepressants said,

Unfortunately there is great difficulty and cost in getting alternative therapies (eg, good quality CBT). It is cheaper, easier and more convenient to reach for the prescription pad.

I know this because I am a prescriber! [P. 111].

As well as writing about alternatives to antidepressants, some participants commented on valuing the general practitioner's role. Others commented on the lack of information that was provided on long-term effects, including withdrawal effects.

I was never fully informed of all side effects, short or longterm. I have kept the information I receive when prescribed when is minimal/basic. [...] I am now only this and last year finding out the permanent damage from medication that the prescriber knew about but didn't tell me. If I had been more fully informed I would not have taken the medication for a long time or at all. [P. 122].

There is a lack of consumer-based information of personal experiences of antidepressants especially coming off and what is happening when an adverse relapse conditions kicks in; that is, how to withdraw safely. Also lack of info on long-term physical effects of staying on antidepressants. [P. 141].

Comments also addressed the perceived need for more support from prescribers with regard to discontinuation of antidepressants.

The difficulty of getting off has been a tough road and taken me years of trying and is something that doctors could be more knowledgeable of and supportive with. [P. 72].

\section{Discussion}

The majority of patients in this study believed that antidepressants alleviated their depression and improved their quality of life to some degree, although $30 \%$ reported 
moderate-to-severe depression while using antidepressants. As reported in 2013, experiences of adverse effects were common. ${ }^{12}$ However, Bet et al's study ${ }^{12}$ did not examine the adverse emotional effects reported in this study nor did it examine the patients' reports of withdrawal symptoms.

Some patients in this study were particularly concerned about severe withdrawal symptoms that undermined their confidence to discontinue should they wish to and therefore limited their choices. In line with this, $45 \%$ patients also believed that they had some level of addiction to the antidepressant. Some patients were also critical of the lack of information given by prescribers with regard to adverse effects, including withdrawal symptoms. Some also expressed disappointment or frustration with the perceived lack of support available to them in managing withdrawal.

A previous study of patients' beliefs regarding adherence to antidepressant maintenance treatment (75 weeks) found that adherence was highest when the perceived need exceeded concerns about safety and lowest when concerns exceeded perceived need. ${ }^{20}$ In this study, some patients reported adhering to treatment because of safety concerns linked to withdrawal symptoms rather than a perceived need for the antidepressant per se. Finally, approximately $25 \%$ participants wrote about the alternative activities and treatments that they believed could aid recovery. One in six wrote about their perceptions of the importance of therapy or counseling either as an alternative to, or in combination with, antidepressant medication.

\section{Strengths and limitations}

This study provides insight into the experiences of patients who chose to use antidepressants for longer term. The study relies on the self-reports of patients. While it could be argued that the high rates of adverse effects result from a biased sample, this seems unlikely as the majority (89.4\%) of patients reported a reduction in depression and other benefits. The study is less informative about patient-perceived effectiveness of antidepressants. Data were not available to allow for an examination of changes in patients' perceptions of antidepressant medication across time, as data with regard to medication histories and experiences of relapse were not collected in the original survey. This needs to be addressed in future studies given the evidence from qualitative research that patients develop more concerns about antidepressant medication as the number of years of antidepressant use increases. ${ }^{21,22}$

\section{Implications for practice}

It has been argued that regular reviews are important with patients on long-term antidepressant treatment to monitor health status and patient preferences about ongoing use. ${ }^{14}$ This study supports these conclusions. Furthermore, patients who wish to discontinue after long-term treatment will need information about what to expect and support to cope with the potentially severe discontinuation effects. Some patients in this study reported benefits from a combination of antidepressant treatment and psychological therapy. There is also evidence that patients experience less relapse if they have received cognitive behavioral therapy. ${ }^{23}$ Hence, it may be helpful for patients to complete a course of cognitive behavioral therapy or other evidence-based therapy prior to discontinuing treatment.

\section{Disclosure}

The authors report no conflicts of interest in this work.

\section{References}

1. Kupfer DJ. Long-term treatment of depression. J Clin Psychiatry. 1991; 52(Suppl 5):28-34.

2. Hirschfeld RM. Clinical importance of long-term antidepressant treatment. Br J Psychiatry Suppl. 2001;179(42):4-8.

3. OECD. Health at a Glance 2013: OECD Indicators. OECD Publishing; 2013. Available from: http://dx.doi.org/10.1787/health_glance-2013-en

4. Moore M, Yuen Ho M, Dunn N, Mullee M, Maskell J, Kendrick T. Explaining the rise in antidepressant prescribing: a descriptive study using the general practice research database. BMJ. 2009;339:b3999.

5. Keller MB, Berndt ER. Depression treatment: a lifelong commitment? Psychopharmacol Bull. 2001;36(Suppl 2):133-141.

6. Nierenberg AA, Petersen TJ, Alpert JE. Prevention of relapse and recurrence in depression: The role of long-term pharmacotherapy and psychotherapy. J Clin Psychiatry. 2003;64(15):13-17.

7. Piek E, van der Meer K, Nolen WA. Guideline recommendations for long-term treatment of depression with antidepressants in primary care: A critical review. Eur J Gen Pract. 2010;16(2):106-112.

8. Geddes JR, Carney SM, Davies C, et al. Relapse prevention with antidepressant drug treatment in depressive disorders: A systematic review. Lancet. 2003;361(9358):653-661.

9. Alonso J, Angermeyer MC, Bernert S, et al. Use of mental health services in Europe: Results from the European Study of the Epidemiology of Mental Disorders (ESEMeD) project. Acta Psychiatr Scand Suppl. 2004; 109:47-54.

10. Hughes $\mathrm{S}$, Cohen D. A systematic review of long-term studies of drug treated and non-drug treated depression. J Affect Disord. 2009;118(1-3): 9-18.

11. Bockting C, Ten Doesschate M, Spijker J, et al. Continuation and maintenance use of antidepressants in recurrent depression. Psychother Psychosom. 2008;77(1):17-26.

12. Bet PM, Hugtenburg JG, Penninx BW, Hoogendijk WJ. Side effects of antidepressants during long-term use in a naturalistic setting. Eur Neuropsychopharmacol. 2013;23(11):1443-1451.

13. Moret C, Isaac M, Briley M. Problems associated with long-term treatment with selective serotonin reuptake inhibitors. J Psychopharmacol. 2009;23(8):967-974.

14. Reid, S, Barbui, C. Long-term treatment of depression with selective serotonin reuptake inhibitors and other newer antidepressants. BMJ. 2010;340:c1468.

15. Andersohn F, Schade R, Suissa S, Edeltraut G. Long-term use of antidepressants for depressive disorders and the risk of diabetes mellitus. Am J Psychiatry. 2009;166(5):591-598.

16. Gibson K, Cartwright C, Read J. Patient-centered perspectives on antidepressant use: A narrative review. Int J Ment Health. 2014;43(1): 81-99. 
17. Goldberg L, Moncrieff J. The psychoactive effects of antidepressants and their association with suicidality. Cur Drug Saf. 2011;6(2):1-7.

18. Read J, Cartwright C, Gibson K. Adverse emotional and interpersonal effects reported by 1829 New Zealanders while taking antidepressants. Psychiatry Res. 2014;206(1):67-73.

19. Bowling A. Research Methods in Health: Investigating Health and Health Services. Buckingham: Open University Press; 1997.

20. Aitkens JE, Nease DE Jr, Klinkman MS. Explaining patients' beliefs about the necessity and harmfulness of antidepressants. Ann Fam Med. 2008;6(1):23-29.
21. Karp. D. Is It Me or My Meds? Living with Antidepressants. Cambridge, MA: Harvard University Press; 2006.

22. Knudsen P, Hansen EH, Traulsen JM, Eskilden K. Changes in selfconcept while using SSRI antidepressants. Qual Health Res. 2002;12(7): 932-944.

23. Hollon SD, DeRubeis RJ, Shelton RC, et al. Prevention of relapse following cognitive therapy vs medications in moderate to severe depression. Arch Gen Psychiatry. 2005;62(4):417-422.

\section{Publish your work in this journal}

Patient Preference and Adherence is an international, peer-reviewed, open access journal that focuses on the growing importance of patient preference and adherence throughout the therapeutic continuum. Patient satisfaction, acceptability, quality of life, compliance, persistence and their role in developing new therapeutic modalities and compounds to optimize clinical outcomes for existing disease states are major areas of interest for the journal. This journal has been accepted for indexing on PubMed Central. The manuscript management system is completely online and includes a very quick and fair peer-review system, which is all easy to use. Visit http://www. dovepress.com/testimonials.php to read real quotes from published authors.

\footnotetext{
Submit your manuscript here: http://www.dovepress.com/patient-preference-and-adherence-journal
} 